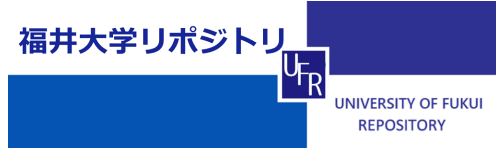

Def or mat $i$ on Behavi or Est i mat $i$ on of Al umi num Foam by $\mathrm{X}$ - $\mathrm{r}$ ay CT I mage- based Fi ni te El ement Anal ysi $s$

\begin{tabular}{|c|c|}
\hline 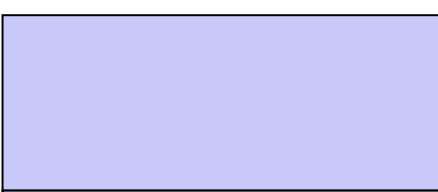 & $\begin{array}{l}\text { HANGAI YOSH H KO, YAMAGUCH RYO, TAKAHASH } \\
\text { SHUNYA, UTSUNOM YA TAKAO, KUMAZURU OSAM, } \\
\text { YOSH KAWA NOBUH RO }\end{array}$ \\
\hline $\begin{array}{l}\text { j our nal or } \\
\text { publ i cat i on titl e }\end{array}$ & Net al I urgi cal and Nat er i al s Transact i ons A \\
\hline vol une & 44 \\
\hline number & 4 \\
\hline page $r$ ange & $1880-1886$ \\
\hline year & $2013-04$ \\
\hline URL & ht t p: //hdl . handl e. net /10098/7458 \\
\hline
\end{tabular}




\title{
Deformation Behavior Estimation of Aluminum Foam by X-ray CT Image-based Finite Element Analysis
}

\author{
YOSHIHIKO HANGAI, RYO YAMAGUCHI, SHUNYA TAKAHASHI, \\ TAKAO UTSUNOMIYA, OSAMU KUWAZURU, and NOBUHIRO YOSHIKAWA
}

\begin{abstract}
Aluminum foam is a lightweight material owing to the existence of a large number of internal pores. The compressive properties and deformation behavior of aluminum foam are considered to be directly affected by the shape and distribution of these pores. In this study, we performed image-based finite element (FE) analyses of aluminum foam using X-ray computed tomography (CT) images and investigated the possibility of predicting its deformation behavior by comparing the results of FE analyses with those of actual compressive tests. We found that it was possible to create an analytic model reflecting the three-dimensional (3D) pore structure using image-based modeling based on X-ray CT images. The stress distribution obtained from imagebased FE analysis correctly indicates the layer where deformation first occurs as observed in actual compressive tests. Also, by calculating the mean stress of each plane perpendicular to the direction of compression based on the stress distribution obtained from image-based FE analysis, it was found that deformation begins in the layer containing the plane with maximum stress. It was thus possible to estimate the layer where deformation begins during the compression of aluminum foam.
\end{abstract}

DOI: $10.1007 / \mathrm{s} 11661-012-1532-7$

(C) The Minerals, Metals \& Materials Society and ASM International 2012

\section{INTRODUCTION}

Metal foams are lightweight materials with excellent impact-energy-absorbing properties, and their use in automobile components is expected to improve fuel consumption and safety. So far, a variety of methods has been proposed for the preparation of metal foams, and the compressive properties and impact-energyabsorbing properties of metal foams have been examined in many studies. ${ }^{[1-6]}$ The compressive properties are thought to be greatly affected by the internal pore structure, but the current understanding of the relation between compressive properties and internal pore structure is limited to discussion based on scant information about the porosity (density) and externally observed changes in the pore structure during compressive deformation. ${ }^{[6-11]}$ It is hoped that a more detailed consideration of information pertaining to the internal pore structure will reveal its effect on the compressive properties of foams and thus enable the production of

YOSHIHIKO HANGAI, Associate Professor, RYO YAMAGUCHI and SHUNYA TAKAHASHI, Graduate Students, are with the Department of Mechanical System Engineering, Graduate School of Engineering, Gunma University, Kiryuu 376-8515, Japan. Contact e-mail: hanhan@gunma-u.ac.jp TAKAO UTSUNOMIYA, Professor, Research Organization for Advanced Engineering, Shibaura Institute of Technology, Saitama 337-8570, Japan. OSAMU KUWAZURU, Associate Professor, Department of Nuclear Power and Energy Safety Engineering, Graduate School of Engineering, University of Fukui, Fukui 910-8507, Japan. NOBUHIRO YOSHIKAWA, Professor, Institute of Industrial Science, The University of Tokyo, Tokyo 153-8505, Japan.

Manuscript submitted May 2, 2012.

Article published online November 13, 2012 metal foams with superior compressive properties as well as the prediction of their properties.

Image-based modeling is a technique that is capable of building analytic models that closely reflect information about a material's three-dimensional (3D) shape. Modeling methods include serial sectioning and X-ray computed tomography (CT), which have been applied to numerous materials such as porous ceramics, ${ }^{[12]}$ skeletal structures ${ }^{[13,14]}$ and pore defects in aluminum alloy die castings. ${ }^{[15,16]}$ Such techniques are also being applied to metal foams. For example, analyses using image-based finite element (FE) analysis have been used to model the actual 3D pore structure of metal foams to predict their stressstrain curves. ${ }^{[17-20]}$ Moreover, studies have elucidated how micropores in cell walls affect the stress distribution in the walls. ${ }^{[21]}$ However, because the morphological information used in these analyses was obtained using serial sectioning and synchrotron radiation X-ray micro tomography over a limited region of observation, almost all of these analyses focused on test specimens with relatively few macro size pores, and the effect of the interaction between pores has therefore not been considered. Moreover, almost no research is currently being conducted on the behavior of successive layer deformation observed during the compression of aluminum foam.

In this study, we attempted the image-based $\mathrm{FE}$ analysis of aluminum foam using general-purpose X-ray CT on compressive test specimens with at least seven pores on each side. When applied to actual products, it is preferred that such analysis targets large regions and that compressive properties, including the site where deformation begins, the types of pores that weaken metal foams, and the magnitudes of the plateau stress and absorption energy, 

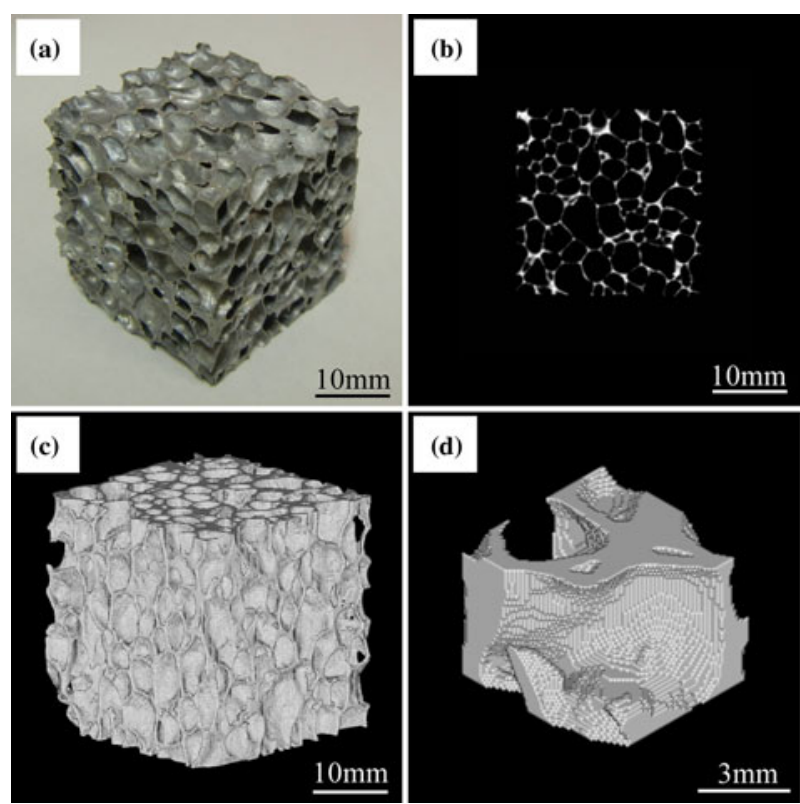

Fig. 1-(a) ALPORAS specimen used in compressive test. (b) Twodimensional cross-sectional X-ray CT image of ALPORAS specimen. (c) Voxel model of ALPORAS specimen. (d) Enlarged voxel model of ALPORAS specimen around pores.

can be predicted by nondestructive means without performing an actual compressive test. Among these properties, the aim of our research is to establish a method for predicting the layer where deformation first occurs. To this end, we first performed X-ray CT imaging of aluminum foam and created an analytic model reproducing in detail the pore structure based on the image data obtained. We then simulated a compressive test by applying imagebased FE analysis to the model. We also performed an actual compressive test on the aluminum foam imaged by $\mathrm{X}$-ray CT and observed its deformation behavior. We then compared the results of both tests to investigate the possibility of predicting the layer in which deformation in aluminum foam begins.

\section{EXPERIMENTAL AND ANALYTICAL METHODS}

\section{A. Test Specimens}

We used commercially available ALPORAS (Shinko Wire Company Ltd.) as the aluminum foam. ${ }^{[22]}$ Cubes of $25 \times 25 \times 25 \mathrm{~mm}^{3}$ were cut from a large ALPORAS block by wire electrical discharge machining (EDM) and used as test specimens. Figure 1(a) shows an external view of an ALPORAS specimen used in a compressive test. In all, 12 test specimens were used. The specimens had porosity $p$ ranging from 88.0 to 90.2 pct, calculated from the dimensions and weight of each cube.

\section{B. X-Ray CT Imaging Method}

X-ray CT imaging was performed using an SMX-225CT microfocus X-ray CT system (Shimadzu Corporation).
Cone-beam CT was used to obtain 3D images. The image size was $512 \times 512 \times 480$ voxels, with each voxel forming a cube of side $74.6 \mu \mathrm{m}$. The X-ray tube voltage was $80 \mathrm{kV}$, and the X-ray tube current was $30 \mu \mathrm{A}$. Figure 1(b) shows an example of a tomographic image obtained by X-ray CT imaging. The white areas are aluminum (cell walls), and the black areas are pores or external air.

\section{Compressive Test Method ${ }^{[23]}$}

After X-ray CT imaging, the specimens were subjected to compressive testing at a cross-head speed of $5 \mathrm{~mm} /$ minutes using an Autograph AG-100kNG universal testing machine (Shimadzu Corporation). At the same time, the deformation behavior of the compressive test specimen undergoing compression was observed by video imaging from a single direction.

\section{Image-Based FE Analysis Method}

An FE analysis model was created by voxel modeling based on the acquired X-ray CT images. VOXELCON 2011 image-based structural analysis software (Quint Corporation) was used for 3D image processing and FE analysis. After layering of the tomographic images to obtain 3D images, a suitable threshold value was selected from a pixel value histogram so that aluminum and pores were distinguished, and image voxels were classified into material voxels and space voxels. X-ray CT image noise was eliminated at this stage by means of a mean filter. The material voxels were then converted into cubic FEs, with one voxel corresponding to one element, to obtain a 3D voxel model such as that shown in Figure 1(c). Figure 1(d) shows a 3D voxel model of the area around pores, which has been extracted and enlarged. It is apparent that each pore is separated by sufficiently fine voxels.

Next, in addition to the voxel models above, the material surface (pore surface) was extracted as an isosurface by means of the threshold value employed for voxel modeling based on the X-ray CT image, and a 3D STL model was created. Individual pore volumes were calculated from this STL model. At this stage, noise was eliminated by a mean filter, after which the pore walls were thickened by two more passes of the maximum filter to prevent the loss of walls thinner than one voxel. Pore volumes were slightly underestimated as a result.

Figure 2 shows the relationship between the pore volume $V$ and the number of pores in a compressive test specimen with a porosity $p$ of 88.9 pct (specimen I). Pores with volumes below $1 \mathrm{~mm}^{3}$ were excluded owing to the limits of X-ray CT precision. ${ }^{[24]}$ This compressive test specimen contained 382 pores with a mean volume of $17.8 \mathrm{~mm}^{3}$ (i.e., a mean pore diameter of $3.24 \mathrm{~mm}$ ). The specimen contained a large number of pores with a range of volumes, and most of these pores were considered to contribute to the compressive properties of the aluminum foam.

A completely fixed base surface and $1 \mathrm{~mm}$ (4 pct) compression of the upper surface of the test specimen were assumed in the FE model via displacement boundary conditions. A linear elasticity analysis was performed 


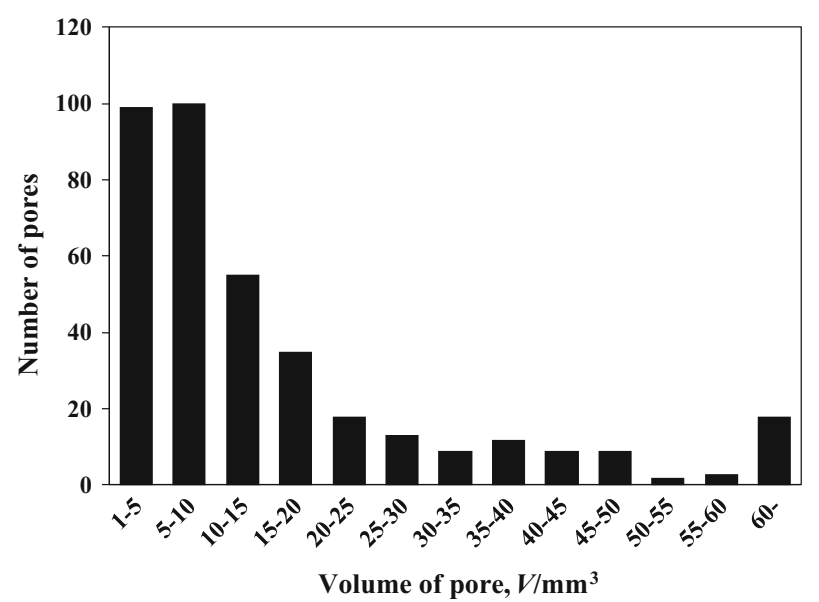

Fig. 2-Relationship between volume $V$ and number of pores observed in 3D STL model of compressive test specimen of ALPORAS (specimen I).

on the cell walls on the assumption that they were pure aluminum with Young's modulus $E=69 \mathrm{GPa}^{[25]}$ and Poisson's ratio $v=0.3$.

The resultant stress was evaluated on the basis of the average element stress, but to eliminate the effect of the stress concentration (excessive stress) due to surface irregularities in the voxel model, the stress on each voxel of interest was taken to be the arithmetic mean of the stress of the voxel of interest and those of the 26 surrounding adjacent voxels in 3D space, that is, a total of 27 voxels. However, at areas such as pore surfaces, where voxels were not surrounded by 26 voxels, the mean value only included material voxels. In addition, to alleviate the excessive stress at boundaries generated as a result of the absence of more than half of the adjacent material voxels, a fine one-voxel layer was inserted above and below the compressive surface.

\section{EXPERIMENTAL AND ANALYTICAL RESULTS AND DISCUSSION}

\section{A. Evaluation of Deformation Layers Based on Stress Distribution}

Figure 3 shows the compressive test results for specimen I ( $p=88.9$ pct). Figure 3(a) shows the nominal stress-nominal strain curve obtained from the actual compressive test, Figure 3(b) shows the initial pore structure of the compressive test specimen before compression, and Figures 3(c) and (d) show deformations at compressive strains of $\varepsilon=12$ pct and $\varepsilon=28$ pct, respectively. As can be seen, deformation begins in the lower layer inside the red frame. The pores in this layer undergo significant compression, whereas the pores in the other layers undergo slight elastic deformation, which can barely be seen. Subsequently, once the red-framed layer has undergone a certain degree of deformation, the blue-framed layer begins to deform, indicating that the material examined in this study, ALPORAS, undergoes deformation that proceeds layer by layer.

Figure 4 shows Mises equivalent stress distributions for the test specimen of Figure 3 (specimen I) obtained by image-based FE analysis for the case of strain applied in the direction of compression (i.e., that in Figures 3(b) through (d)). The images in Figures 4(a) through (c)
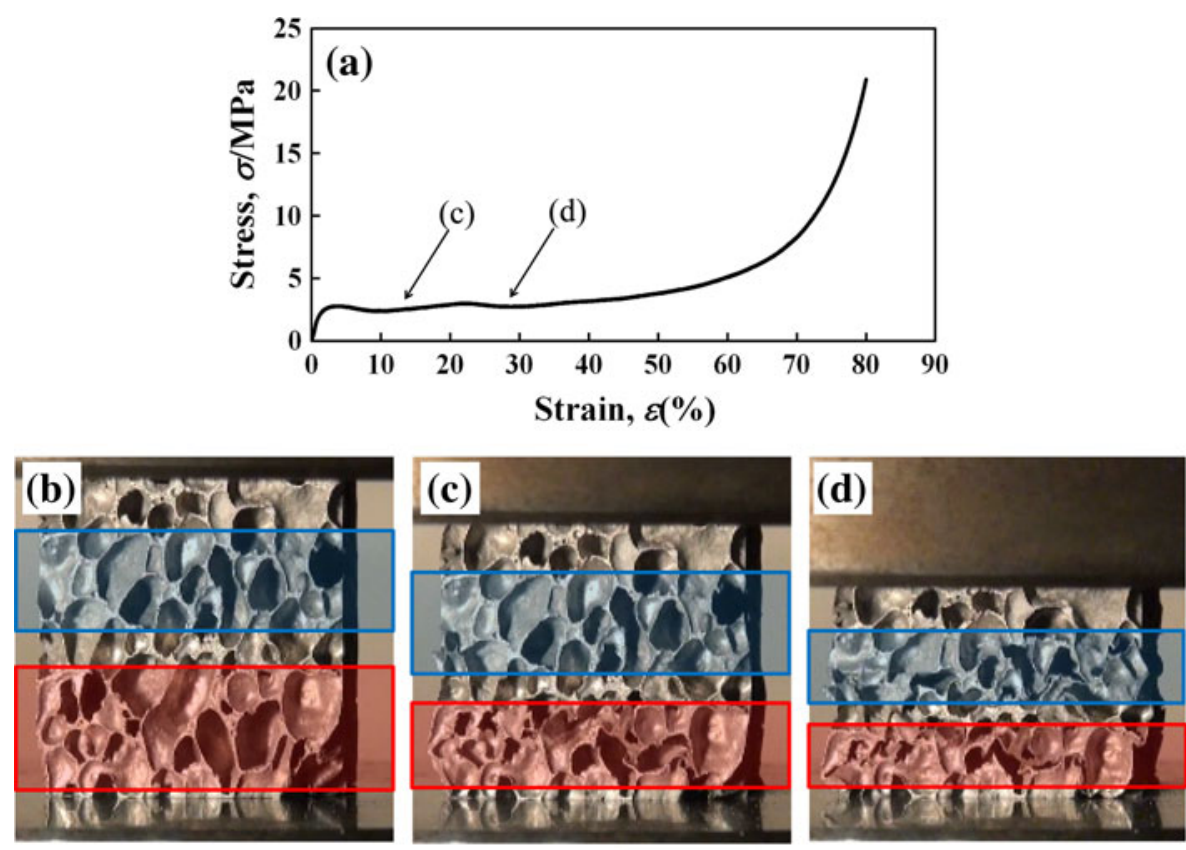

1st deformation layer

2nd deformation layer

Fig. 3-Compressive behavior of ALPORAS specimen I $(p=88.9 \mathrm{pct})$ : $(a)$ stress-strain curve, $(b)$ initial pore structure, $(c)$ pore structure at compressive strain of $\varepsilon=12$ pct, and $(d)$ pore structure at compressive strain of $\varepsilon=28$ pct. 

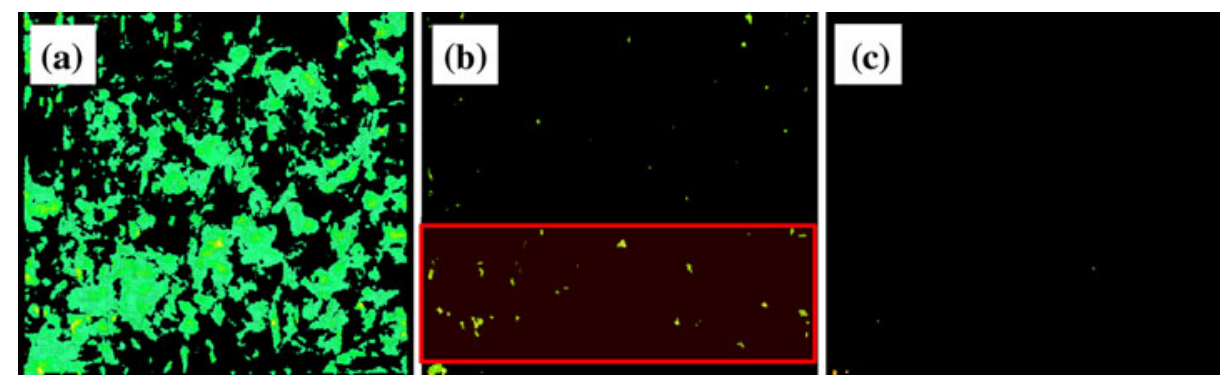

Fig. 4-Mises equivalent stress distributions for ALPORAS specimen I obtained by image-based FE analysis where the stress was greater than (a) $2 \sigma_{\mathrm{m}},(b) 3 \sigma_{\mathrm{m}}$, and (c) $4 \sigma_{\mathrm{m}}$.

show stress distributions with different ranges of stress based on the results of image-based FE analysis of the same test specimen. The colored contours show voxels with stress greater than two, three, and four times the mean Mises equivalent stress $\sigma_{\mathrm{m}}$ of all the voxels in the test specimen. In Figure 4(a), it is apparent that the display range is too wide and that the specimen contains many low-stress regions, whereas in Figure 4(c) the low-stress regions have been excessively eliminated and almost all of the voxels have been removed. For this study, we therefore decided to set the display range as that shown in Figure 4(b), which encompasses voxels with stress greater than $3 \sigma_{\mathrm{m}}$.

Similarly to in Figure 3, the layer where deformation begins is indicated by a red frame in Figure 4(b). Voxels with comparatively high stress are abundantly distributed in the red-framed region, whereas high stress is almost absent from the upper part of the test specimen, where no change was observed under a compression of $\varepsilon=12$ pct. Namely, it appears that the layer where deformation begins and the high-stress region correspond with each other.

Figure 5 shows the compressive behavior of the specimen with porosity $p=88.8$ pct (specimen II). Figure 5(a) shows the initial pore structure, Figure 5(b) shows the stress distributions obtained by image-based FE analysis, and Figure 5(c) shows the deformation at a compressive strain of $\varepsilon=12$ pct. Similarly to in Figures 3 and 4, there is a clear correspondence between the locally deformed layer and the high-stress region. This trend was also apparent in most other test specimens. The above observations indicate that, by means of image-based FE analysis used to observe the stress distribution, it is possible to predict, at least qualitatively, the layer where aluminum foam deformation begins.

\section{B. Evaluation of Deformation Layer From the Mean Stress in Planes Perpendicular to the Direction of Compression}

In the previous section, we examined the possibility of predicting the layer where deformation begins from the stress distribution. However, in a few cases, this prediction is difficult. Figure 6 shows the compressive behavior of a test specimen with porosity $p=89.8 \mathrm{pct}$ (specimen III). Figure 6(a) shows the initial pore structure, Figure 6(b) shows the stress distributions obtained by image-based FE analysis, Figure 6(d) shows the deformation at a compressive strain of $\varepsilon=12$ pct, and Figure 6(e) shows the nominal stress-nominal strain curve obtained from the actual compressive test. As shown in Figure 6(b), specimen III has high-stress voxels distributed over its entirety, and there is no obvious relationship between the layer where deformation begins and the stress distribution. We therefore calculated the mean stress $\sigma_{1}$ on each plane perpendicular to the direction of compression, as shown in Figure 6(c), and evaluated the specimen after normalization by the mean Mises equivalent stress $\sigma_{\mathrm{m}}$ of all the voxels in the test specimen. Here, the stress in each plane of interest was taken to be the mean value of the stress
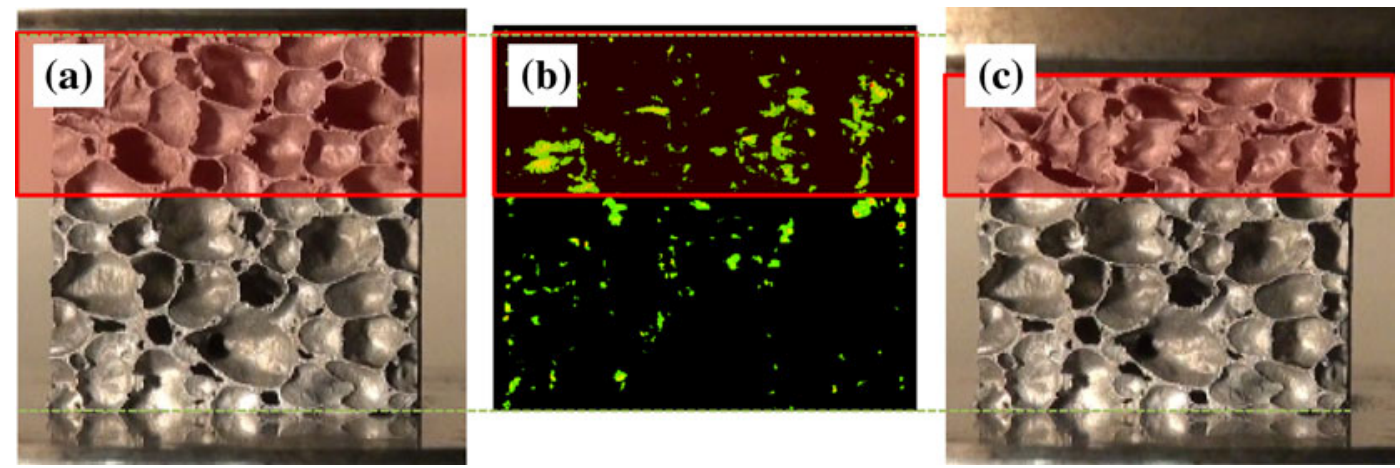

Fig. 5-Compressive behavior of ALPORAS specimen II $(p=88.8 \mathrm{pct})$ : $(a)$ initial pore structure, $(b)$ stress distribution obtained by imagebased FE analysis, and $(c)$ pore structure at compressive strain of $\varepsilon=12$ pct. 

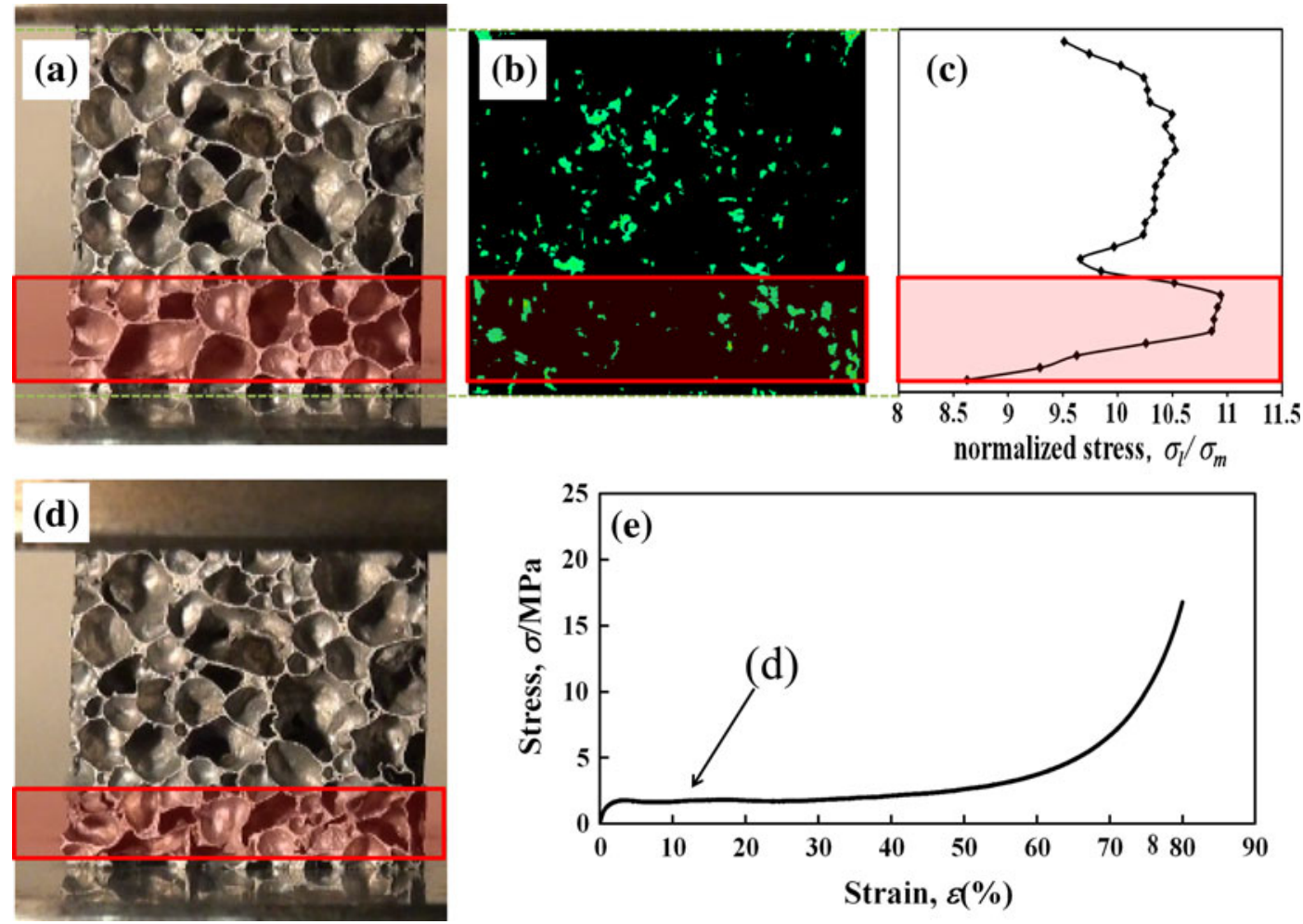

Fig. 6 - Compressive behavior of ALPORAS specimen III $(p=89.8 \mathrm{pct})$ : $(a)$ initial pore structure, $(b)$ stress distributions obtained by imagebased FE analysis, $(c)$ mean stress distribution of planes obtained by image-based FE analysis, $(d)$ pore structure at compressive strain of $\varepsilon=12$ pct, and $(e)$ stress-strain curve.
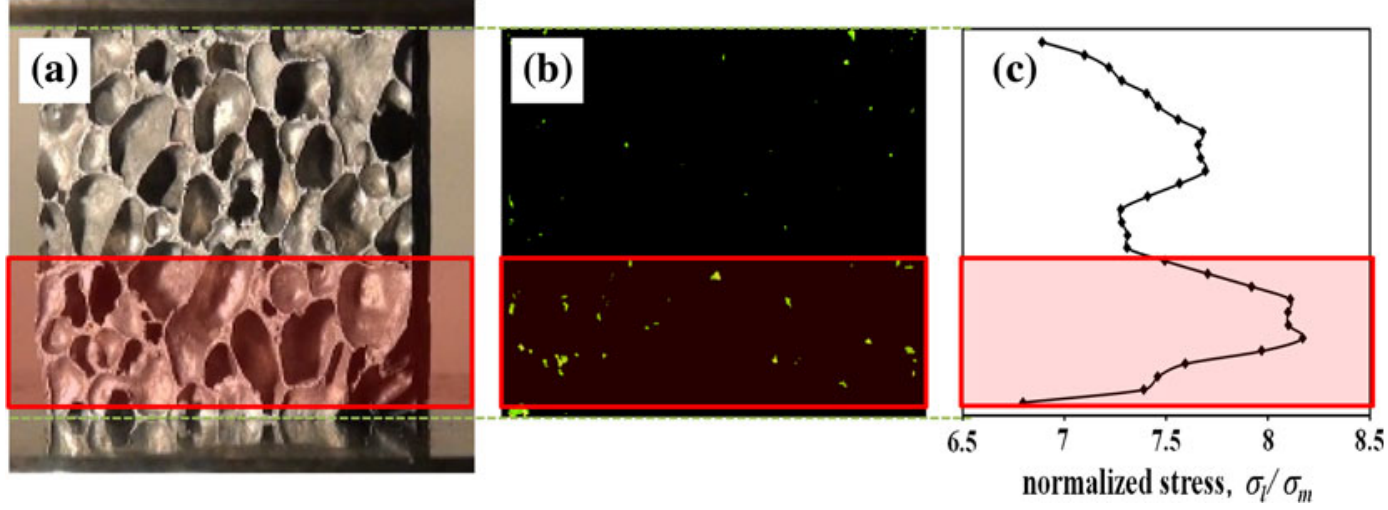

Fig. 7-Compressive behavior of ALPORAS specimen I ( $p=88.9$ pct) (previously shown in Figures 3 and 4): (a) initial pore structure, (b) stress distribution obtained by image-based FE analysis, and (c) mean stress distribution of planes obtained by image-based FE analysis.

of 10 voxels (approximately half of the mean pore diameter) in the planes above and below the plane of interest. It is apparent from the distribution in Figure 6(c) that the plane with the largest stress is inside the red frame where deformation first begins. Figure 7(a) shows the initial pore structure of specimen I ( $p=88.9$ pct) (reproduced from Figure 3), Figure 7(b) shows the stress distribution obtained by imagebased FE analysis (reproduced from Figure 4), and Figure 7(c) shows the value of $\sigma_{1} / \sigma_{\mathrm{m}}$ for each plane. A clear correspondence exists between the locally deformed layer and the planes with high stress. A similar correspondence was observed in most other test specimens, suggesting that it is possible to estimate the layer where deformation begins by image-based FE analysis.

\section{Evaluation of Deformation Layer Obliquely Inclined to the Direction of Compression}

In this study, we evaluated the test specimens with the assumption that deformation occurs in layers perpendicular to the direction of compression. This is because such deformation is expected to occur in an actual aluminum foam, particularly in ALPORAS, which is manufactured from pure aluminum. However, cases have been reported in which deformation occurs 
(a)
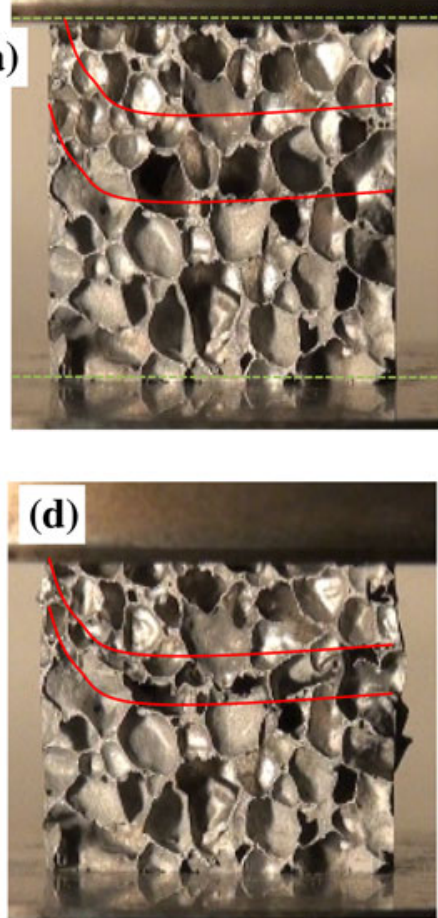

(b)
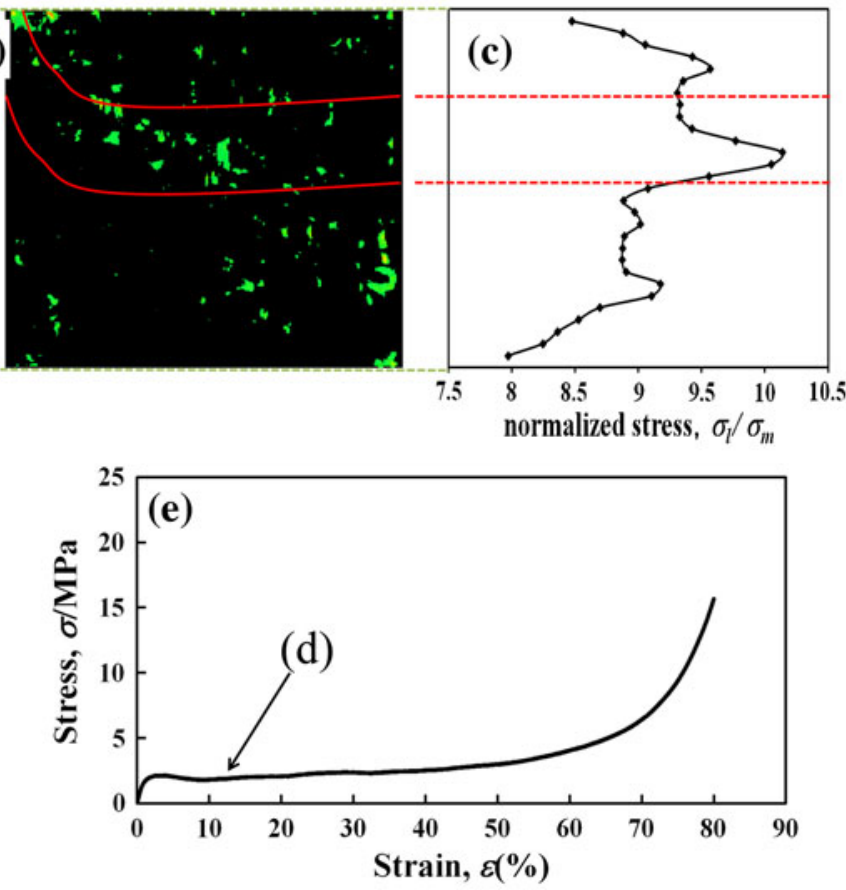

Fig. 8-Compressive behavior of ALPORAS specimen IV ( $p=90.2$ pct): $(a)$ initial pore structure, $(b)$ stress distribution obtained by imagebased FE analysis, $(c)$ mean stress distribution of planes obtained by image-based FE analysis, $(d)$ pore structure at compressive strain of $\varepsilon=12$ pct, and (e) stress-strain curve.

obliquely to the direction of compression. ${ }^{[10,11]}$ Figure 8 shows the deformation behavior of a compressive test specimen with porosity $p=90.2$ pct (specimen IV). As shown in Figures 8(a) and (d), a large part of the specimen begins to deform in a layer perpendicular to the direction of compression, but the remaining part undergoes oblique deformation. A more precise image could have been obtained by evaluating the stress distribution in planes with a variety of orientations. However, even when the aluminum foam deforms obliquely in compressive tests, the angle of deformation relative to the perpendicular direction is small, and the region with oblique deformation is small, meaning that it is reasonable to assume that perpendicular deformation is the dominant deformation mode. As shown by the results of the image-based FE analysis in Figures 8(b) and (c), the region where deformation occurs in layers perpendicular to the direction of compression corresponds to the region with high stress and the planes with highest $\sigma_{1} / \sigma_{\mathrm{m}}$. Accordingly, it is thought that an approximate evaluation is possible even if deformation in only the perpendicular direction is studied, as focused on in this study. Further research is thus necessary.

It is anticipated that these methods of predicting the layer where deformation first occurs can be extended to aluminum foams for which control of the order of deformation is essential, for example, functionally graded aluminum foams, ${ }^{[26-30]}$ fabrication of which has been attempted in recent years. In functionally graded aluminum foams, deformation is controlled by optimizing the type of alloy and the arrangement of characteristics of the pore structure, such as porosity and pore size. However, in practice, it is difficult to experimentally test all combinations of these characteristics. If some assumptions are made on the deformation behavior of such foams, then analysis should make it possible to evaluate the properties of functionally graded aluminum foam for use as a structural component.

\section{CONCLUSIONS}

In this study, we performed image-based FE analyses of aluminum foam using X-ray CT images and investigated the possibility of predicting its deformation behavior by comparing the results of FE analyses with those of actual compressive tests. We obtained the following results:

1. It was possible to create an analytic model reflecting the 3D pore structure using image-based modeling based on X-ray CT images.

2. The stress distribution obtained from image-based $\mathrm{FE}$ analysis and the layer where deformation first begins observed in actual compressive tests corresponds with each other. It was thus possible to predict the layer where deformation first occurs during the compression of aluminum foam.

3. By calculating the mean stress of each plane perpendicular to the direction of compression from the stress distribution obtained from image-based FE analysis, it was found that deformation begins in the layer containing the plane of maximum stress. It was thus possible to estimate the layer where 
deformation begins during the compression of aluminum foam.

4. In some cases, aluminum foam deformed obliquely under compression. However, an approximate evaluation should be possible under the assumption that deformation occurs in a layer perpendicular to the direction of compression.

\section{ACKNOWLEDGMENTS}

This study was partly financially supported by the Industrial Technology Research Grant Program in 2009 from the New Energy and Industrial Technology Development Organization (NEDO) of Japan and JKA promotion funds from AUTORACE. The authors thank Professor K. Saito, Gunma University, for his helpful advice on conducting the experiments, and T. Miyoshi, Shinko Wire Company, Ltd., for providing ALPORAS.

\section{REFERENCES}

1. M.F. Ashby: Metall. Trans. A, 1983, vol. 14, pp. 1755-69.

2. A.G. Evans, J.W. Hutchinson, and M.F. Ashby: Prog. Mater Sci., 1998, vol. 43, pp. 171-221.

3. L.J. Gibson: Ann. Rev. Mater. Sci., 2000, vol. 30, pp. 191-227.

4. A.G. Evans, J.W. Hutchinson, N.A. Fleck, M.F. Ashby, and H.N.G. Wadley: Prog. Mater Sci., 2001, vol. 46, pp. 309-27.

5. J. Banhart: Prog. Mater Sci., 2001, vol. 46, pp. 559-632.

6. H. Nakajima: Prog. Mater Sci., 2007, vol. 52, pp. 1091-1173.

7. A.F. Bastawros and A.G. Evans: Adv. Eng. Mater., 2000, vol. 2, pp. $210-14$.

8. A.F. Bastawros, H. Bart-Smith, and A.G. Evans: J. Mech. Phys. Solids, 2000, vol. 48, pp. 301-22.

9. A.E. Markaki and T.W. Clyne: Acta Mater., 2001, vol. 49, pp. $1677-86$.

10. D.J. Werther, A.J. Howard, J.P. Ingraham, and K.A. Issen: Scripta Mater., 2006, vol. 54, pp. 783-87.
11. M. Hakamada, T. Kuromura, Y. Chino, Y. Yamada, Y.Q. Chen, H. Kusuda, and M. Mabuchi: Mater. Sci. Eng. A, 2007, vol. 459, pp. 286-93.

12. N. Takano, M. Zako, F. Kubo, and K. Kimura: Int. J. Solids Struct., 2003, vol. 40, pp. 1225-42.

13. S.J. Hollister and N. Kikuchi: Biotechnol. Bioeng., 1994, vol. 43, pp. 586-96.

14. Y. Shiino, O. Kuwazuru, and N. Yoshikawa: J. Theor. Biol., 2009, vol. 259, pp. 132-41.

15. Y. Hangai, O. Kuwazuru, T. Yano, T. Utsunomiya, Y. Murata, S. Kitahara, S. Bidhar, and N. Yoshikawa: Mater. Trans., 2010, vol. 51, pp. 1574-80.

16. N. Vanderesse, E. Maire, A. Chabod, and J.Y. Buffiere: Int. J. Fatigue, 2011, vol. 33, pp. 1514-25.

17. E. Maire, A. Fazekas, L. Salvo, R. Dendievel, S. Youssef, P. Cloetens, and J.M. Letang: Compos. Sci. Technol., 2003, vol. 63, pp. 2431-43.

18. T. Kujime, M. Tane, S.K. Hyun, and H. Nakajima: Mater. Sci. Eng. A, 2007, vol. 460, pp. 220-26.

19. I. Jeon, T. Asahina, K.-J. Kang, S. Im, and T.J. Lu: Mech. Mater., 2010, vol. 42, pp. 227-36.

20. N. Michailidis, F. Stergioudi, H. Omar, and D. Tsipas: Comput. Mater. Sci., 2010, vol. 48, pp. 282-86.

21. H. Toda, M. Takata, T. Ohgaki, M. Kobayashi, T. Kobayashi, K. Uesugi, K. Makii, and Y. Aruga: Adv. Eng. Mater., 2006, vol. 8, pp. $459-67$.

22. T. Miyoshi, M. Itoh, S. Akiyama, and A. Kitahara: Adv. Eng. Mater., 2000, vol. 2, pp. 179-83.

23. JIS-H-7902: Method for Compressive Test of Porous Metals, Japanese Standards Association, 2008.

24. Y. Hangai, S. Maruhashi, S. Kitahara, O. Kuwazuru, and N. Yoshikawa: Metall. Mater. Trans. A, 2009, vol. 40A, pp. 2789-93.

25. The-Japan-Institute-of-Light-Metals: Structures and Properties of Aluminum, The Japan Institute of Light Metals, 1991, pp. 413-18.

26. A. Pollien, Y. Conde, L. Pambaguian, and A. Mortensen: Mater. Sci. Eng. A, 2005, vol. 404, pp. 9-18.

27. A.H. Brothers and D.C. Dunand: Mater. Sci. Eng. A, 2008, vol. 489, pp. 439-43.

28. K. Shinagawa: in Porous Metals and Metallic Foams, L.P. Lefebvre, J. Banhart, and D. Dunand, eds., Destech Pubns Inc, 2008, pp. 95-98.

29. Y. Hangai, Y. Oba, S. Koyama, and T. Utsunomiya: Metall. Mater. Trans. A, 2011, vol. 42A, pp. 3585-89.

30. Y. Hangai, K. Takahashi, T. Utsunomiya, S. Kitahara, O. Kuwazuru, and N. Yoshikawa: Mater. Sci. Eng. A, 2012, vol. 534, pp. 716-19. 